\section{A Participação Popular Na Governança Da Água Como Reforço À Cidadania Ambiental Nas Democracias Da América Latina}

\author{
Diego Monte Teixeira
}

Mestrado em Direito Constitucional pela Universidade de Fortaleza (UNIFOR)

\section{Newton Menezes Albuquerque}

Doutor em Direito pela Universidade Federal de Pernambuco (UFPE). Professor Titular da Universidade de Fortaleza (UNIFOR) e professor Associado 2 da Universidade Federal do Ceará (UFC).

Resumo: O artigo tem o objetivo de analisar os desafios da participação popular na governança da água na América Latina, especialmente as repercussões dessa participação na democracia, na reelaboração de seus conceitos e realidades, tanto na gestão dos escassos recursos naturais, como também no tratamento mais amplo, ético, do nexo entre direitos e natureza. Com um campo de estudo centrado na área das ciências jurídicas, foi utilizado o método jurídico-técnico através do raciocínio dedutivo na análise de algumas Constituições de países de América Latina, doutrinas, jurisprudências de Tribunais Internacionais, além de artigos científicos, para concluir que a introdução da ideia de cidadania ambiental requer um redimensionamento das relações entre homem e natureza, sociedade e cultura, superando os unilateralismos presentes numa concepção antropocêntrica que tem orientado tradicionalmente o lugar da pessoa no interior do Estado. Os resultados apresentados são no sentido de que o incremento da cidadania ambiental nas democracias da América Latina tem de passar pela participação popular na governança da água, a qual deve ser concebida como um direito humano ao invés de uma mercadoria qualquer.

Palavras-chave: Água; Cidadania; Democracia; América Latina.

\section{UNIVERSIDADE FEDERAL DA PARAÍBA}




\title{
A Participação Popular Na Governança Da Água Como Reforço À Cidadania Ambiental Nas Democracias Da América Latina
}

\author{
Diego Monte Teixeira
}

Newton Menezes Albuquerque

\section{INTRODUÇÃO}

A humanidade está a vivenciar uma crise brutal de gestão da água. Estudos da Organização Mundial de Saúde do ano de 2000 já estimavam que 1.1 bilhão de pessoas não tinham acesso a adequado abastecimento de água nas proximidades de sua residência e aproximadamente 2.4 bilhões de pessoas não tinham acesso a qualquer serviço de saneamento básico (WHO e UNICEF, 2000). O estudo, a par de apontar que o aumento da população mundial acarretaria mais problemas para o acesso a esse recurso natural, que integra o rol de direitos humanos básicos, aponta que as iniciativas dos grupos de pessoas podem trazer melhorias rápidas e duradouras para a garantia da universalização do acesso a esse bem.

Segundo Lucon (2013, p. 41), aproximadamente a metade das bacias hidrográficas mundiais é internacional. Os cursos d'água internacionais criam oportunidades de externalizar custos, por uso inadequado ou por poluição quando do acesso a este recurso natural, que é o mais crítico à saúde pública e ao desenvolvimento socioeconômico dos países. 
Sob o viés do neoliberalismo, que apoia e fomenta uma ideia alargada de que o mundo todo passa por uma crise de disponibilidade hídrica, as mais variadas ações e propostas estão a se desenvolver sobre a mercantilização da água, como mecanismo de regulação da relação oferta-demanda de recursos hídricos. Assim é que muitas regiões fronteiriças são potenciais palcos de conflito na América Latina em razão da busca e da privatização desse recurso, buscando assim maximizar os ganhos do Capital, extraindo da natureza lucros crescentes.

Os diversos agrupamentos sociais têm buscado, sobretudo a partir da segunda metade do século XX e após as grandes guerras mundiais, a construção de alternativas democráticas para a resolução de seus problemas. Os Estados e os blocos de Estados foram impulsionados a erigir um aparato institucional e jurídico para gerenciar os conflitos socioambientais, que se intensificaram nesta nova era de hiperconsumismo, notadamente em razão dos interesses geopolíticos que movimentam os Estados no âmbito de seus espaços nacional e regional.

Dentro desse cenário, a Organização das Nações Unidas ONU aprovou em 2010 uma Resolução que aponta a água e o saneamento como direitos humanos, que derivam do direito a um padrão de vida adequado e indispensável para a realização de outros direitos humanos, e que deve orientar uma política de governança da água pelas comunidades internacionais.

No âmbito da América Latina, além dos deveres do Poder Público e da coletividade para a preservação ambiental estarem previstos nas diversas Constituições dos Estados que a integram, há o direito da coletividade de ser comunicada das decisões estatais sobre a matéria.

O reconhecimento da água como um direito humano, decorrente do direito ao meio ambiente ecologicamente equilibrado e do direito à saúde e à vida digna, apresenta-se como desafio às ambiguidades da globalização. De um lado, as corporações 
internacionais atuam vorazmente para se apropriarem desse precioso recurso natural, de outro, na esteira do que afirma Oliveira et. al. (2014, p. 273), redesenham-se os sujeitos de direitos como sujeitoscidadãos dotados de poder decisório, já não mais exclusivo do Estado, e que se entendem como corresponsáveis pela gestão do meio ambiente.

Diante desse quadro, o trabalho se propõe a discutir alternativas democráticas aos mecanismos de mercantilização da água, por meio da governança popular de tal recurso na América Latina, o que se dá com a própria aplicabilidade das normas constitucionais dos Estados Democráticos de Direito, que estão a apontar para um projeto humanista de participação direta dos cidadãos nos rumos da política. Tal propósito encontra-se alinhado ao conceito de hegemonia e de socialização do poder que, para Gramsci (2000, p. 287), representa "a passagem molecular dos grupos dirigidos a grupos dirigentes” em que a apropriação do poder pelas maiorias da sociedade civil se dá gradativamente, acompanhado de uma elevação espiritual no plano da consciência dos sujeitos políticos.

Trata-se de uma pesquisa qualitativa e exploratória que está dividida em três tópicos: no primeiro, abordar-se-á a crise de gestão da água e o enfoque da questão hídrica pelo neoliberalismo; no segundo, efetua-se uma defesa contra as ameaças de privatização da água, a partir da exortação de uma cidadania ambiental ativa na América latina; e, por fim, serão apresentados alguns exemplos de reforço democrático na América Latina na governança da água a partir do reforço dos mecanismos de controle comunitário do poder local, regional e nacional. 


\section{A CRISE DE GESTÃo DA ÁGUA E O ENFOQUE DADO PELO NEOLIBERALISMO}

Segundo Hans Jonas (2006, p. 231), a natureza não poderia ter corrido um risco maior do que este de haver produzido o homem e Aristóteles jamais poderia supor que a sua teoria da totalidade da natureza (physis) - que apregoava que a integração das partes que a conformam, garantir-lhe-ia a higidez no todo -, viria a ser contestada pelo presumido domínio antropocêntrico, este, paradoxalmente, marcado pela desumanidade. Na verdade, a totalidade em nosso tempo capitalista exacerbou a fratura entre homem e natureza, subjugando ambos à lógica da acumulação desenfreada, alienada do dinheiro.

Estudos de campo confirmam a diminuição da qualidade dos serviços ambientais em função da perda da biodiversidade decorrente da deterioração dos ecossistemas por atividades humanas, o que está a acarretar um grande espasmo de extinção de espécies (WILSON, 1994, p. 373). Da mesma forma, atividades de poluição e desflorestamento têm contribuído decisivamente para as alterações climáticas (IPCC. 2014).

A humanidade está a vivenciar um ecocídio generalizado, resultante de um processo cultural do capitalismo de hiperconsumismo, complementado por padrões de descartabilidade inéditos dos produtos, de desperdício de matérias-primas, de concentração de renda e de poder inauditos em relação a outros períodos históricos. Tal cultura atinge até as classes empobrecidas, pois que, na era do hiperconsumidor, todos aqueles que não dispõem de condições de se inserirem no mercado de consumo passam a ser considerados como fracassados, como subclasse, excluídos sociais enquadrados nas estatísticas como "pessoas abaixo da linha de pobreza" (BAUMAN, 2008, p. 85). 
Esse quadro é dramaticamente agravado pelas consequências desoladoras do aniquilamento do equilíbrio ambiental, precipuamente na periferia capitalista, o que, muitas vezes, tem tornado inviável a organização da convivência humana com o meio ambiente, levando a migração de massas populacionais significativas para os países desenvolvidos, com toda repercussão na elaboração de políticas particularistas, repressivas sobre os migrantes pobres. Tendência esta, responsável, entre outros fatores, pela expansão de medidas draconianas, nacionalistas, de contenção das migrações e de reforço dos aspectos autocráticos na consecução do Estado de Exceção por dentro das presumidas democracias ocidentais.

No que toca aos recursos hídricos, apenas 0,007\% do total de água do Planeta Terra é de água doce de fácil acesso para o uso humano. Segundo Machado (2003, p. 122), a poluição dos mananciais, o desmatamento, o assoreamento dos rios, entre outras ações do homem moderno, contribuem para que mais de 1,3 bilhão de pessoas careçam de água doce no mundo, sendo que o consumo humano de água duplica a cada 25 anos, aproximadamente.

A água doce, na forma como encontrada nos continentes, é essencial para o desenvolvimento das atividades do homem. A água salgada do oceano não é útil para beber, lavar, cozinhar, irrigar ou para a maioria das aplicações na indústria, sendo que o processo de dessalinização é bastante caro, demanda muita energia e é viável apenas para um número limitado de aplicações. Além disso, a água salgada está disponível somente no litoral, enquanto a maior necessidade de água está no interior (HOEKSTRA et al., 2011, p. 17).

O The United Nations World Water Development Report, resultado da participação conjunta de 23 (vinte e três) agências da ONU, apresentado em Kyoto, em 2003, apontou que faltará água para cerca de 2 (dois) bilhões de pessoas, na visão otimista, e para cerca de 7 (sete) bilhões, no cenário pessimista, em 2050 (RIBEIRO, 2003, p. 71). 
A Participação Popular Na Governança Da Água Como Reforço...

No Relatório Mundial das Nações Unidas para o Desenvolvimento de Recursos Hídricos 2016, a Organização das Nações Unidas para a Educação a Ciência e a Cultura (UNESCO), em nome da ONU Água, além de destacar que a redução da disponibilidade de água causa impactos graves no mercado de trabalho, ressalta que:

As economias da América Latina e do Caribe dependem fortemente da exploração dos recursos naturais, incluindo a água, principalmente para mineração, agricultura, incluindo biocombustíveis, silvicultura, pesca e turismo. Isso exige atenção constante dos tomadores de decisões políticas, a fim de maximizar a contribuição da água para o desenvolvimento e a criação de empregos, iniciando com negociações institucionais sólidas, transparentes e eficazes para a gestão hídrica integrada e a prestação de serviços de água e saneamento(United Nations Educational, Scientific and Cultural Organization - UNESCO, 2012).

A tensão pelo uso da água, entretanto, não decorre apenas de sua pouca disponibilidade, mas sobretudo pela sua irregular distribuição entre os territórios e sua má gestão pelos Estados. Na América Latina, especificamente, há abundância do recurso, pois se estima que juntos os países andinos e o Brasil detenham cerca de 1/4 (um quarto) do estoque de água doce mundial, razão pela qual Ribeiro (2008, p. 131) conclui que a carência de água só pode ser explicada pela ausência de políticas públicas que permitam a adoção de um sistema de coleta, tratamento e distribuição de água para a população local.

Augusto et. al. (2012, p. 1513) anotam que a água está distribuída de forma desigual no planeta, tanto entre os tipos de mananciais, quanto entre as regiões e intrarregionalmente. Entre os tipos de mananciais, afirmam os autores, apenas 0,3\% (zero vírgula três por cento) da água doce está em mananciais superficiais e cerca de 30\% (trinta por cento) no subsolo, e a maior parte, cerca de 70\% (setenta por cento), está em geleiras. Para contrastar a desigualdade 
de distribuição dos recursos hídricos com as diferenças

populacionais, os autores apresentam a seguinte tabela:

Tabela 1. Distribuição percentual dos recursos hídricos e populacionais no Mundo por continentes.

\begin{tabular}{|c|c|c|}
\hline Continentes & $\begin{array}{c}\text { Percentual da população } \\
\text { mundial }\end{array}$ & $\begin{array}{c}\text { Percentual da quantidade } \\
\text { de água superficial } \\
\text { disponível }\end{array}$ \\
\hline África & $15,0 \%$ & $10,0 \%$ \\
\hline Américas & $13,6 \%$ & $41,0 \%$ \\
\hline Ásia & $59,8 \%$ & $31,6 \%$ \\
\hline Europa & $10,9 \%$ & $7,0 \%$ \\
\hline Oceania/Austrália/Antártida & $0,5 \%$ & $10,3 \%$ \\
\hline
\end{tabular}

A boa disponibilidade de água na América Latina, quando comparada com outras regiões do planeta, e a conclusão de que a crise hídrica na região é diretamente afetada pela crise de governança também são confirmadas no documento publicado em 2001 pela Divisão de Recursos Naturais e Infraestrutura da Comissão Econômica para a América Latina e o Caribe (CEPAL, 2001).

Segundo o documento, para enfrentar a questão do acesso à água, sugeriu-se o desenvolvimento e o manejo integrado dos recursos hídricos, de tal maneira que o processo deve considerar aspectos qualitativos e quantitativos, bem como os interesses múltiplos relacionados ao uso da água. O manejo integrado deve se orientar na percepção da água como parte integrante do ecossistema, a ser realizado no nível de bacia ou sub-bacia de captação, além de basear-se nas necessidades e prioridades de cada comunidade.

Contudo, muitas das soluções para o adequado gerenciamento da água na região, ao invés de se voltarem para a conscientização da comunidade sobre a preciosidade do recurso e a implementação de políticas estatais para uma distribuição equânime da água, têm se 
dado dentro do processo de mercantilização da água estimulada pelo Banco Mundial. E, como ressalta Shiva:

\begin{abstract}
[...] projetos de privatização financiados pelo Banco Mundial e outras agências de fomento são em geral rotulados como parcerias público-privadas. O rótulo é forte, tanto pelo que sugere quanto pelo que esconde. Ele indica a participação do público, a democracia e a responsabilidade de prestar contas. Mas encobre o fato de que os arranjos das parcerias público-privadas, em geral, vinculam a utilização de fundos públicos na privatização de bens públicos (SHIVA, 2006, p. 109).
\end{abstract}

É relevante mencionar que, desde o final da década de setenta do século passado, graças à disseminação de discursos pela Organização das Nações Unidas (ONU) e pelo Banco Mundial sobre a escassez de água em nível global, a temática da valoração econômica da água como forma de efetivação da sustentabilidade e segurança hídricas globais já ganhava visibilidade na agenda política internacional (SILVA et. al., 2010. p. X).

Os autores acima mencionados, ao citarem algumas ações da ONU, como o Fórum Mundial da Água em Haia no ano 2000, na qual se reuniram grandes organizações de lobby comercial na área de recursos hídricos como as corporações Vivendi e Suez, e outras medidas do Banco Mundial, como o Relatório Água, Redução da Pobreza e Desenvolvimento Sustentável (2003), apontam que a proposta de gestão integrada de recursos hídricos, com o estabelecimento de parcerias até o nível internacional, quebra a lógica do caráter nacional/regional da administração do referido recurso e, intencionalmente, desvia o foco do seu interesse mercadológico.

Assim, o alargamento da situação caótica da crise hídrica pelo movimento neoliberal, que transmuda a questão principal que é de gestão da água, para o foco da disponibilidade do recurso, é terrível para a América Latina. Quando se imagina que os enormes impactos humanos causados à natureza conduziriam a humanidade a refletir 
sobre uma nova ética do cuidado, e para uma maior conscientização da sociedade enquanto legitimada para decidir assuntos de seu próprio interesse, a agenda capitalista se apropria da situação com o enfoque que mais lhe convém para colher novos dividendos.

Ressalte-se que as propostas de mercantilização da água, em regra por meio de Parcerias Público-Privadas (PPPs), não resolve o problema da população pobre. Antes, termina por agravá-lo. É que pela lógica global de valoração da água, o que se observa, a nível mundial, é que $40 \%$ (quarenta por cento) da água do planeta são consumidos por $20 \%$ (vinte por cento) da população que vive em países desenvolvidos e que tem condições de pagar pelo recurso (CAUBET, 2004, p. 20).

3 CONTRA AS AMEAÇAS DE PRIVATIZAÇÃO: POR UMA CIDADANIA AMBIENTAL ATIVA NA AMÉRICA LATINA NO USO SUSTENTÁVEL DA ÁGUA

Ao tratar da tradição constitucionalista latino-americana, no que concerne à ausência de direitos aos recursos naturais e à agua, Wolkmer et al. (2012, p. 54) rememora que tanto a cultura sociopolítica imposta pelas Metrópoles no período colonial, quanto as instituições formadas após o processo de independência nas antigas colônias ibéricas, derivam da tradição europeia, representada pelo modelo de Estado e de democracia representativa. Anotam que a herança das cartas políticas burguesas e dos princípios iluministas inerentes às declarações de direitos, bem como o legado proveniente da modernidade capitalista do livre-mercado e da inserção do liberalismo individualista, representaram um papel importante no processo de positivação do Direito estatal na região. 
Sob a ótica da denominada "governança", que, segundo Fonseca e Bursztyn (2009, p. 21), adveio da disseminação de ideias e de práticas neoliberais ao longo do último quarto do século passado, ligada a um amplo processo de redução do Estado e à valorização da incorporação de atores externos no processo político e na gestão de políticas públicas, constata-se o crescimento de propostas de mercantilização da água nos Estados latino-americanos.

Não se desconhece a crítica formulada por Castro (2013, p. 196), no sentido de que o processo de mercantilização da água é pelo menos tão antigo quanto a história escrita, e que seria necessário distinguir as commodities da água da mercantilização capitalista da água, que estaria restrita a um universo relativamente pequeno de usos da água doce. Entende-se, contudo, que a troca generalizada de água como mercadoria em mercados genuinamente capitalistas não é tão rara como aponta o autor, tanto assim que no princípio 4 da Declaração de Dublin, da Conferência Internacional da Água e do Ambiente, ocorrida em 1992, a água foi declarada um "bem econômico" em todos os seus usos competitivos.

Como aponta Bruckmann (2011, p. 226), o controle da água na América do Sul representa o controle de uma das principais fontes renováveis de água doce do planeta, de um enorme potencial de energia hidrelétrica, o controle de um dos sistemas ecológicos de maior concentração de biodiversidade do mundo, ou seja, a floresta amazônica, os picos ecológicos da região andina, os grandes lagos da Patagônia e os lagos inter-andinos. Ressalta a autora que os interesses em disputa são enormes e que os Estados Unidos necessitam assegurar o abastecimento de água doce, haja vista que o nível de seu consumo está acabando com suas reservas de água subterrânea.

Para Silva et. al. (2006, p. 31), os argumentos dos que defendem a mercadorização da água como mecanismo básico de regulação da relação oferta-demanda de recursos hídricos protegem do questionamento o modo de produção capitalista, como indutor de 
uma série de incômodos no acesso aos recursos hídricos para grande parte da população mundial. Martins et. al. demonstram o impacto negativo da criação de mercados de água parra o exercício da cidadania:

\begin{abstract}
O impacto que a criação de mercados de água traz parra o exercício da cidadania precisa ser considerado urgentemente, sobretudo porque o cidadão está acima do consumidor no que concerne às garantias constitucionais de proteção dos direitos. Conforme mostra Castro (1998), os direitos sociais, como educação, saúde, proteção contra indigência, dentre outros, constituem as condições mínimas para a participação plena de qualquer indivíduo em sua comunidade e assim também para o exercício efetivo dos direitos e das obrigações da cidadania civil e política. Sem os direitos sociais reais (e não somente formais), a população que não possui condições de comprar educação, a saúde e no caso em questão - a água em mercados, fica excluída também da cidadania civil e política (MATINS et. al., 2004, p. 34).
\end{abstract}

No cenário mercadológico, a água é um privilégio da camada social mais rica, enquanto a maioria pobre padece com a sua escassez. Observam-se, nesse cenário, os subsídios governamentais usuais no financiamento da água pelos empreendimentos capitalistas, numa clara e inequívoca demonstração do caráter da ação do Estado em prol da racionalidade de realização do valor no âmbito do sistema. A situação, na leitura de Barlow e Clarke (2003, p. 91), mantém direta relação com a compra de todos os suprimentos de água por interesses privados, sendo que, nos países do "Terceiro Mundo”, a privatização da água é exigida para renegociação das dívidas externas e faz com que seus cidadãos não sejam capazes de pagar os crescentes custos tarifários de tal recurso.

Como anota Boron (1994, p. 13), a liberdade e a democracia sucumbem quando se está diante de situações extremas: a generalização da extrema pobreza, de um lado e o fortalecimento da plutocracia, de outro. Assim, afirma o autor, permanece válida a crítica socialista às inconsistências de um regime cujos predicados 
A Participação Popular Na Governança Da Água Como Reforço...

igualitários e democráticos são incongruentes com suas premissas práticas classistas e autoritárias.

Ora, os modernos Estados Democráticos de Direito devem se fundar tanto na liberdade política quanto na igualdade de participação dos cidadãos perante o poder e as questões afetas à sociedade, o que, infelizmente, não ocorre devido a colonização dos mecanismos políticos, jurídicos e culturais pela plutocracia hegemônica. Por via de consequência, as sociedades civis, expandidas em seu ethos democrático e abertas a novas perspectivas de controle social, não podem se descurar da participação da gestão da água, única forma de cercear o abuso do capital e de seus agentes sobre a dinâmica de apropriação e uso dos recursos hídricos escassos nas sociedades contemporâneas, inclusive na formação dos preços sobre o seu consumo.

Morais e Nascimento (2010, p. 30), em considerações acerca de uma nova cidadania, a partir de uma visão comunitária e antagônica à liberal, destacam a necessidade de retomada do conceito de cidadania ativa, calcada no pensamento de Aristóteles, tendo o indivíduo como fruto da comunidade, retomando a centralidade da política, da dignidade de seus pressupostos públicos, abertos, comunicativos e continuamente reconstrutores do real. A política que como bem o sabia o estagirita, não era algo artificial, imposto de fora, mas, pelo contrário, nascida da sociabilidade inata do homem, de seu carecimento ontológico por articular processos sociais de cooperação e de identidade.

Da mesma forma, os autores destacam a discussão travada por Bryan Turner, sobre a cidadania passiva, a partir de cima, via Estado, e a cidadania ativa, a partir de baixo, via ativa. Aliás, como também se deu, quando da emergência das Cidades-Estado na Itália renascentista, quando os humanistas cívicos delimitaram outra vez o poder com base nos condicionamentos locais oriundos dos reclamos da comunidade. Redefinição esta que encontrou em Maquiavel seu mais lídimo acabamento sob fundamentos normativos específicos, 
essenciais para o reconhecimento posterior do estatuto do Estado Nacional nos pródromos da modernidade. Ou seja, geralmente, em momentos de crise civilizatória, os termos da relação entre ordem político-jurídica e ambiente, solicitam novos marcos de intelecção, imprescindíveis para a plena integração de seus elementos na ordem normativa e social da vida dos homens.

Desde a Declaração de Estocolmo de 1972, tida como um marco do Direito Ambiental Internacional, já se aponta a necessidade de assunção de responsabilidades por parte dos cidadãos e das comunidades na partilha de esforços comuns para o enfrentamento da crise ambiental global. Tal concepção seria também reforçada na Declaração Rio de 1992 quando, no princípio 10, aponta que a melhor maneira para equacionar as questões ambientais é assegurar a participação, em nível apropriado, de todos os cidadãos interessados.

A par dessa visão procedimentalista concernente à utilização dos direitos humanos à informação, à participação nos processos de decisão e de acesso a mecanismos jurídicos e administrativos de controle para a proteção do meio ambiente, Carvalho ressalta que:

[...] a proteção ambiental seria alcançada, disponibilizando a cada cidadão, em nível nacional, o acesso adequado às informações relativas ao meio, de que disponham as autoridades públicas, inclusive as referentes a materiais e atividades perigosas existentes em suas comunidades, bem como oportunizando aos indivíduos a participação nos processos de tomada de decisões (CARVALHO, 2008, p. 29).

Como decorrência dos avanços da compreensão entre a relação da proteção do meio ambiente e a fruição de direitos humanos, constata-se que, no âmbito da América Latina, não só as obrigações do Poder Público para a preservação do meio ambiente ecologicamente equilibrado estão previstas nas diversas Constituições dos Estados, como também o dever da própria coletividade de proteger a higidez ambiental e o direito de ser 
A Participação Popular Na Governança Da Água Como Reforço...

comunicada das decisões estatais sobre a matéria. É o que prescreve, por exemplo: o artigo 225 da Constituição do Brasil, o art. 97 da Constituição da Guatemala, o art. 115 da Constituição do Panamá, o artigo 88 da Constituição do Equador, o art. 127 da Constituição da Venezuela, entre outros. Mais do que isso, na América Latina o "novo constitucionalismo" tem avançado sobre a própria questão dos vínculos entre sociedade e natureza, ao dotar esta última de subjetividade jurídica, capaz de provocar a jurisdição estatal na tutela de seus direitos.

Nesse sentido, a gestão democrática da água situa-se nos marcos de uma nova abordagem da economia, do direito, da perspectiva problematizadora das ciências com sua realidade, não só humana. Afinal a defesa da vida, da biodiversidade do planeta, das formas variadas de cooperação dos laços de trabalho, dos ritmos de produção, consumo e distribuição dos produtos depende, ou deveria depender, de uma compreensão mais generosa, responsável, aberta e democrática com nossos recursos, principalmente, os ambientais.

Assim é que a gestão da água deve ser realizada de modo compartilhado, com ampla participação dos cidadãos, e a partir da ideia da água como um direito humano, para que os interesses da sociedade civil sejam respaldados e seus direitos também cobrados, pois como anota Roesler (2012, p. 123), é preciso ter cuidado permanente para que as políticas públicas não se distanciem dos princípios democráticos e participativos da cidadania, de questões relacionadas aos problemas socioambientais, defesa dos novos direitos fundamentais com base natural de sustentabilidade das formas de vida: humana e não humana. 


\section{ALGUNS EXEMPLOS DE REFORÇO DEMOCRÁTICO NA AMÉRICA LATINA NA GOVERNANÇA DA ÁGUA}

Em defesa da tese de uma ressignificação substancialmente democrática e solidária da governança da água, Turatti (2014, p. 206) propõe um pensamento a partir do contexto local, como ponto de partida, no qual haja a busca pela informação para a participação qualificada ou emancipação do processo de comunicação pública, integradora das demandas de todos os grupos da sociedade envolvidos com as questões em debate.

Observa-se que as organizações de base da sociedade para a tomada de decisões sobre a gestão da água abrem espaços para a participação popular e para o aprofundamento da democracia. No Brasil, por exemplo, a concepção de gestão pública colegiada dos recursos hídricos, a partir dos comitês de bacias hidrográficas, permite que os usuários da água se organizem e participem ativamente dos comitês, de forma a defender seus interesses quanto aos preços a serem cobrados pelo uso, assim como sobre a aplicação dos recursos arrecadados e sobre a concessão justa das outorgas dos direitos de uso (JACOBI; BARBI, 2007, p. 240).

O modelo brasileiro, em termos normativos, pode ser considerado de destaque na América Latina, na medida em que a participação popular na gestão dos recursos hídricos ocorre de forma institucionalizada e prevista na Política Nacional de Recursos Hídricos (Lei 9.433/97), por intermédio dos comitês de bacia hidrográfica, dos conselhos estaduais e nacional de Recursos Hídricos.

Conquanto contemple a necessidade de promoção do empoderamento da sociedade na elaboração e na implementação da Política Nacional de Recursos Hídricos, com o objetivo de fortalecer os canais de comunicação existentes e a criação de novos, assim como 


\section{A Participação Popular Na Governança Da Água Como Reforço...}

o aperfeiçoamento dos meios de interlocução social, o Sistema Brasileiro de Gestão dos Recursos Hídricos não esclarece de que forma se propõe a fazê-lo (TURATTI, 2014, p. 204).

Um exemplo de excelência da gestão da água no Brasil, a partir da participação ativa da sociedade interessada, é relatado por Ahlert (2013, p. 1581) acerca do Município de Marechal Cândido Rondon, no Estado do Paraná. Segundo o autor, o referido município alcançou 100\% (cem por cento) de abastecimento de água para a população rural através do sistema de Associações de Usuários "Águas Rurais", em que todo o processo, e até mesmo os serviços de manutenção da rede física de distribuição da água, é organizado pelos próprios moradores de uma Linha Rural a partir da criação de sua associação e sob a orientação técnica da autarquia municipal Serviço Autônomo de Água e Esgoto (SAAE).

Na Venezuela, a partir de sua Constituição Nacional adotada em 1999 e do incremento da participação popular no processo político venezuelano, está a se desenvolver um modelo de participação do usuário na gestão da água, através das denominadas Mesas Técnicas da Água (MTAs), que são as organizações comunitárias previstas na Lei Orgânica para a Oferta dos Serviços de Água Potável e Esgotamento Sanitário (LOPSAS).

Com a entrada em vigência da LOPSAS e as mudanças introduzidas nas Empresas Públicas de Oferta de Água e Esgoto (EPPAS), juntamente com a ação das MTAs, tem-se construído um novo tipo de relação comunidade-Estado, que não está mediada por atores privados nem por organizações não governamentais (LACABANA, 2015, p. 270).

Ainda segundo Lacabana (2015, p. 273), quando de sua avaliação da forma como tem se dado esse novo governo participativo da água, com base na experiência de vários anos de trabalho em diferentes comunidades (barrios de invasión) de setores populares da Venezuela, as MTAs canalizam a participação das comunidades para obter, melhorar, manter e vigiar um serviço de água e esgoto de 
qualidade para seus assentamentos, assim como para criar uma cultura da água que valorize e cuide deste recurso. A relação das MTAs com os organismos públicos está baseada em uma visão de corresponsabilidade e identidade com o serviço, e tal estratégia tem contribuído decisivamente com o objetivo de ampliar o acesso da população à água potável e ao esgotamento sanitário e, também, de cumprir antecipadamente com as metas do milênio na Venezuela estipuladas pela $\mathrm{ONU}$.

Outro tipo de gestão popular da água na América Latina se deu através de um dos movimentos mais significativos de enfrentamento do comércio da água em Cochabamba na Bolívia. Jim Shultz descreve sinteticamente o que ocorreu na referida região:

\begin{abstract}
Antes de abril de 2.000 poucas pessoas de fora da Bolívia haviam ouvido falar sobre Cochabamba, uma cidade de 600.000 habitantes cravada em um vale andino a 8.000 pés de altura. Quatro meses após o início do novo século esse quadro mudou. Cochabamba se tornou a linha de frente da crescente batalha internacional contra as regras da globalização econômica. Enfrentando soldados, resistindo à declaração de uma lei marcial e se levantando contra a onda da teologia do mercado econômico, a população mais pobre da América do Sul expulsou uma das empresas mais ricas do mundo e reconquistou algo simples e básico - sua água (SHULTZ, 2003, p. 1).
\end{abstract}

Trata-se de um movimento popular contra o processo de privatização da Empresa Municipal de Água Potável e Saneamento SEMAPA, por meio de uma concessão a uma empresa filiada à multinacional BECHTLE, na década de 1990, com o objetivo de abater dívidas contraídas pelo governo boliviano junto ao Banco Mundial. Saliente-se que o contrato de concessão para os operadores

\footnotetext{
${ }^{1}$ As metas do milênio para o acesso à água potável, programadas para 2015 pela Organização das Nações Unidas, foram alcançadas pela Venezuela com mais de uma década de antecedência, como, por exemplo, a cobertura de água potável na Região Metropolitana de Caracas que aumentou de 86\%, em 1998, para 95\%, em 2004 (Venezuela, 2005).
} 


\section{A Participação Popular Na Governança Da Água Como Reforço...}

do Aguas del Tunari continha cláusulas que se mantiveram confidenciais mesmo após a venda da SEMAPA e permitiam a indexação das tarifas através do dólar americano e estabelecia a meta de inversão total do capital investido antes mesmo da conclusão da obra (DRUMOND, 2015, p. 193).

A privatização, que havia se dado com o pretexto de reduzir os custos do poder público com o oferecimento de água e conferir maior qualidade e eficiência dos serviços oferecidos pelo capital privado e estrangeiro, logo resultou numa catástrofe para os cidadãos cochabambinos. Apenas poucas semanas depois de assumir o controle da água, a empresa da Bechtel apresentou às famílias locais um aumento de 200\% na taxa de água. Trabalhadores que viviam com o salário mínimo local de 60 dólares deveriam pagar algo como 15 dólares para continuar com água correndo de suas torneiras (FREITAS; BORGES, p. 180, 2014).

Preocupados com a privatização da água e a nova lei aprovada, os aproximados 10 (dez) mil cidadãos, sob uma organização que ficou conhecida como La Coordinadora, iniciaram um movimento para reivindicar seus direitos, desafiando a política do governo. Após diversos protestos populares, sem êxito, La Coordinadora liderou o que ficou conhecido como La Ultima Batalla contra o governo e o consórcio de empresas da água, paralisando a cidade por mais quatro dias numa verdadeira Guerra da Água, sendo que, ao final, a nação mais pobre da América Latina venceria uma das maiores corporações internacionais e a política capitalista para água na Bolívia (FREITAS; BORGES, p. 185, 2014).

A partir de então, a Bolívia passou a uma nova forma de gestão da água, assim descrito por Barlow:

La gente se hizo cargo de esta nueva dificultad y eligió un nuevo consejo de administración para la compañía de aguas, desarrollando un nuevo mandato anclado en un firme conjunto de principios. La compañía tenía que ser eficaz; incorruptible, justa para con los trabajadores, guiarse por su compromiso hacia la justicia social (abasteciendo primer o a los que no tienen agua), y 
actuar como catalizador para una mayor participación y organización del movimiento popular. La primera medida de la nueva compañía consistió en poner en funcionamiento una enorme cisterna de agua en los barrios menos favorecidos del sur, instalando cañerías para el abastecimiento de 400 localidades que se habían visto abandonadas por la antigua compañía. Después, la empresa se preocupó en tener una presencia dinámica en los barrios, escuchando a la gente y trabajando con ella para resolver los problemas. (BARLOW, 2004, p. 16).

A partir dessa nova perspectiva e sob o forte princípio da soberania popular, a Constituição da Bolívia de 2009 prevê, nos artigos 16 e 20, que toda pessoa tem direito à água e ao acesso universal e equitativo aos serviços básicos de água potável, enquanto um direito humano fundamental. Do mesmo modo, foi a Bolívia quem apresentou a proposta, que mais tarde (em 2010) viria a ser aprovada como uma Resolução pela Organização das Nações Unidas - ONU, que aponta a água e o saneamento básico como direitos humanos.

Esse processo liga-se a um exame mais profundo, que supera os paradigmas clássicos como pensamentos sobre a política, o direito e a democracia, pois questiona os fundamentos das clivagens tradicionais em que se esteiam a compreensão sobre o mundo, as instituições, o próprio poder do Estado. O padrão generalizado a partir do iluminismo liberal por um racionalismo instrumental, entre outros efeitos, sempre balizou sua visão da natureza como elemento secundário de sua reflexão. A certeza de que a ruptura entre natureza e cultura, legitimava todas as formas de subjugação daquela pelo homem, mais precisamente, do sistema de produção de mercadorias, foi pouco refletido na história da civilização humana. Daí a legitimação do uso exauriente dos recursos ambientais, assim como a de sua vinculação às demandas da mercantilização econômica, presumidamente a favor da geração de empregos e de bem-estar entre as pessoas.

Contudo, com a constatação da destruição das condições de vida, das trágicas alterações climáticas e da possibilidade da 


\section{A Participação Popular Na Governança Da Água Como Reforço...}

ocorrência de resultados cataclísmicos que possam vir, inclusive, a por termo a existência da espécie humana, começou-se a se interpelar o consenso paradigmático que pautou a ideia de progresso na civilização ocidental de cunho liberal. Chega-se ao ponto de alguns pensadores proporem, como forma de combate ao modelo antropocêntrico-burguês, vorazmente consumista e destruidor da natureza, que ingressemos no estágio do decrescimento econômico. Pois segundo os referidos pensadores, somente com um radical reposicionamento com a matriz produtivista que definiu o capitalismo, poderemos repactuar nossas relações com a natureza e consigo mesmos, numa reconciliação ética do mundo.

O surgimento, quando da elaboração da Constituição do Equador de 2008, do conceito de Direito da Natureza, requer da humanidade, uma revisão de nossa condição ontológica, marcada pela crença em nossa singularidade não natural, como seres artificialmente políticos, como propugnam os contratualistas de distintos matizes e orientações ideológicas, demanda um novo e sensível olhar sobre a questão. Afinal como bem apregoa Alberto Acosta em seu livro "O Bem Viver", a natureza humana integra natureza, com ela compartilha processos comuns e níveis de consciência de sua inscrição no interior da vasta vida. Lidar com água, como com outros seres da natureza, não pode ser circunscrito a uma dimensão objetal, pragmática, sob a ótica do produtivismo econômico dos mercados, mas sob uma abordagem responsável, tanto da vida orgânica da natureza, como da vida "inteligente", reflexiva das comunidades humanas plurais, com graus diversos de desenvolvimento.

A democracia, portanto, como o sabiam os gregos, Rousseau, Marx, Gramsci e tantos outros, não deve ser acatada como mero "regime das maiorias" imediatas, das suas pulsões e desejos, pois também ela dimana um fundamento ético-político, em maior intensidade ainda do que outras formas de ordenação do poder em maior ou menor divórcio com o homem e sua identidade 
emancipatória. Vínculos democráticos de poder na modernidade contemporânea exigem um diálogo para além do humano, que ultrapasse o compromisso com a satisfação material e cultural das pessoas, de suas necessidades "naturais" e criadas, mas também com a natureza que nos antecede, conforma e limita, inexoravelmente.

\section{CONSIDERAÇÕES FINAIS}

A soberania popular e a participação cidadã ativa são diretrizes que devem balizar as sociedades nomeadamente democráticas da América Latina, pois como já advertia Abraham Lincoln, a democracia é o governo do povo, pelo povo e para o povo. Na medida em que as sociedades empresárias se apropriam da água enquanto uma mercadoria e subtraem do povo o poder de gestão do referido recurso, subtraem de boa parte do povo também o usufruto de tal recurso e, com isso, violam um dos direitos mais caros à humanidade e aniquilam a base democrática do governo. Nesse passo, a soberania não mais deve ser tida como um conceito eminentemente de domínio, de estratificação hierárquico-espacial do poder do Estado, mas ser ressignificada, adquirindo uma feição de reafirmação da vontade comunitária sobre as pressões indevidas e ilegítimas dos capitalistas.

Em meio às contradições que acometem as sociedades nomeadamente democráticas, mas com o enorme potencial de categorizar os seres humanos num processo excludente do

capitalismo de consumismo desenfreado, comunga-se do entendimento de Fabre (2003, p. 41) no sentido de que a reflexão sobre o aprimoramento dos princípios que regularam a democracia desde os tempos da Grécia antiga de Platão e Aristóteles, dentre os 
A Participação Popular Na Governança Da Água Como Reforço...

quais o princípio da cidadania, tem mais utilidade do que a tentativa de profetizar futuras soluções para superar impasses democráticos no presente.

O desafio da contemporaneidade pós-moderna tem como um dos seus pilares centrais, a da reelaboração dos elos do homem com a natureza, com as inadiáveis tarefas que levem a criação de um novo poder sensível ao homem e a natureza. Um novo poder democrático que supere dialeticamente as tensões de um projeto de modernidade pautado num desenvolvimento precário da ideia de desenvolvimento que infla os aspectos economicistas da produção, deixando ao largo as dimensões ecológicas, humanistas de uma democracia que se pretenda autêntica. Afinal, a democracia somente será efetivamente democrática se for humanista, ecologicamente responsável pelo homem e os outros seres, e livre da subjugação do Capital, do regime acumulativo perverso que pensa a produção pela produção, e nunca em razão da promoção da felicidade, da "eudaimonia" pregada pelos gregos.

Não se vislumbra um caminho único e bem definido para a melhoria da gestão da água, e tampouco para o incremento da cidadania ambiental nas democracias da América Latina, senão que os trilhos deste processo têm de passar pela participação popular a qual deve se ater à natureza de direito humano do referido recurso natural, e não mercadológica. Participação popular que não se resume ao âmbito dos Estados nacionais, mas que precisa se estabelecer de maneira mais convincente na esfera internacional, forjando instância com poder de decisão sobre o curso da mobilidade do Capital e de suas inciativas de restrição dos direitos fundamentais, principalmente da democracia e de sua capacidade instituinte da realidade.

Curiosamente é no bojo da periferia do capitalismo mundial, mais precisamente na América Latina, junto aos países andinos, que a crítica ao modelo clássico de Estado, de democracia divorciada da 
preocupação com o meio-ambiente, mais tem se desenvolvido. Fruto das lutas acirradas das comunidades indígenas, do enfrentamento com os colonizadores europeus, com a lógica mercantil, com as indústrias extrativistas, a concepção de um direito da natureza, de inovadores modelos de democracia radical, autêntica, plurinacional tem encontrado terreno favorável para construção de uma outra legitimidade político-constitucional, refundando todo espectro das relações éticas do homem consigo mesmo e com a natureza cósmica.

Os modelos de gestão da água no Brasil, na Venezuela e na Bolívia mencionados no bojo do trabalho são apenas exemplos de como se construir espaços para a consolidação da autonomia popular e o incremento da cidadania na América Latina. Ao lado da efetivação do direito humano à água, também se pode constituir novos sujeitos políticos e fazer com que a soberania popular torne a ocupar um lugar central nas sociedades democráticas latino-americanas. Mais do que isso, em alguns casos e países, transforma a própria natureza em sujeito político e jurídico, capaz de responsabilizar a sociedade, os grupos econômicos pelos eventuais danos causados a natureza.

Não se nega um viés socialista da abordagem do estudo, antes comunga-se do entendimento de Guimarães (1999, p. 254) e com ele tenta somar forças, com o propósito de resgatar o sentido nuclear da obra de Marx, que tem muito mais um caráter humanista e libertário da sociedade, do que a feição autoritária defendida, em larga escala, por uma concepção determinista da história. Além de buscar resgatar, para além até das formulações marxianas, outros aspectos, contradições e tendências do tempo presente, que nos levam a uma devida atualização de seu legado crítico e emancipatório. Diálogo com a realidade, com outros referenciais teóricos e normativos, que deve fugir da tentação do dogmatismo fossilizado, da mera reiteração das velhas fórmulas, sem atentar para os inauditos processos que nos desafiam, aliás, desde as mais priscas eras. 
A Participação Popular Na Governança Da Água Como Reforço...

A democracia está sob fortes ameaças no mundo contemporâneo. Todavia, poucas vezes na história tivemos condições propícias para desenvolvê-la tão amplamente, num entrecruzamento de categorias, espaços e temporalidades. A democracia política, social, ambientalmente situada e por tudo isso eticamente fundamentada pede passagem, só precisamos ter coragem cívica e energia intelectual para arrostar os desafios de nosso tempo.

Data de Submissão: 20/08/2017

Data de Aprovação: 25/03/2018

Processo de Avaliação: double blind peer review

Editor Geral: Jailton Macena de Araújo

Editor de Área: Fernando Joaquim Ferreira Maia

Assistente de Edição: Ilina Cordeiro de Macedo Pontes

\section{REFERÊNCIAS}

ACOSTA, Alberto. O Bem Viver: uma oportunidade para imaginar outros mundos. São Paulo: Autonomia Literária,Elefante, 2016. 264 p.

AHLERT, Alvori. Ação comunicativa e ética no acesso e uso sustentável da água: a experiência do saneamento rural de Marechal Cândido Rondon - Paraná. Horizonte, Belo Horizonte, v. 11, n. 32, out./dez. 2013, p. 1571-1588.

AUGUSTO, Lia Giraldo da Silva et al. O contexto global e nacional frente aos desafios do acesso adequado à água para consumo humano. Ciênc. saúde coletiva, Rio de Janeiro, v. 17, n. 6, 2012, p. 1511-1522. 
BARLOW, Maude; CLARKE, Tony. Ouro Azul: Como as grandes corporações estão

se apoderando da água doce do nosso planeta. Tradução de

Andréia Nastri. São

Paulo: M. Books do Brasil, 2003.

BAUMAN, Zygmunt. Vida para consumo: a transformação das pessoas em

mercadorias. Tradução de Carlos Alberto Medeiros. Rio de Janeiro: Zahar, 2008.

BOND, P. Water commodification and decommodification narratives: pricing and policy debates from Johannesburg to Kyoto to Cancun and back. Capitalism Nature Socialism, 15, 2004, p. 1725. Disponível em (doi): <10.1080/1045575032000188957>. Acesso em: set. 2016.

BÓRON, Atílio. Estado e Capitalismo na América Latina. São Paulo: Paz e Terra, 1994, 272 p.

BRUCKMANN, Monica. Ou inventamos ou erramos: a nova conjuntura latino - americana e o pensamento crítico. Tese de Doutorado de Monica Bruckmann, Departamento de Ciência Política - UFF, Niterói, 28 de fevereiro de 2011.

CARVALHO, Edson Ferreira de. Meio Ambiente como patrimônio da humanidade: princípios fundamentais. Curitiba: Juruá, 2008.

CASTRO, José Esteban. A água (ainda) não é uma mercadoria: aportes para o debate sobre a mercantilizaçao da água. Rev. UFMG. Belo Horizonte v. 20 n. 2, jul./dez. 2013, p. 190-221.

CAUBET, Christian Guy. A água, a lei, a política... e o meio ambiente? Curitiba:

Juruá, 2004.

CEPAL, 2001. Crisis de gobernabilidad en la gestión del água: desafios que enfrenta la implementación de las 
A Participação Popular Na Governança Da Água Como Reforço...

recomendaciones contenidas en el capítulo 18 del

Programa 21. Disponível em:

$<$ http://repositorio.cepal.org/bitstream/handle/11362/6395/1/So11

21072 es.pdf $>$. Acesso em 10 de fevereiro de 2017.

DRUMOND, Nathalie. A guerra da água na Bolívia: a luta do movimento popular contra a privatização de um recurso natural. Revista NERA. Presidente Prudente Ano 18, nº .28 - Edição Especial, 2015, p. 186-205.

FONSECA, Igor Ferraz; BURSZTYN, Marcel. Banalização da sustentabilidade: reflexões sobre governança ambiental em escala local. Revista Sociedade e Estado, vol. 24, jan.-abr., p. 17-46, 2009.

FREITAS, Luna; BORGES, Júlia. O direito à água conquistado por meio da luta: guerra da água em Cochabamba. UCSal, Salvador, 2014.

GOYARD-FABRE, Simone. O que é democracia? A genealogia filosófica de uma grande aventura humana. 1 ed. São Paulo: Martins Fontes, 2003.

GRAMSCI, A. Cadernos do cárcere. Tradução de Carlos Nelson Coutinho e colaboração de Luiz Sergio Henriques; Marco Aurélio Nogueira. Rio de Janeiro: Civilização Brasileira, v. 2, 2000.

GUIMARÃES, Juarez. Democracia e marxismo: crítica à razão liberal, São Paulo: Xamã, 1999.

IPCC, 2014: Sumário para os tomadores de decisão do Quinto relatório de avaliação (2014). Traduzido por Iniciativa Verde, São Paulo, 2015. Disponível em: <http://www.iniciativaverde.org.br//lib/php/download.ph p?cfg=1\&arq=produtos/37_2015_05_04_relatorio_ipcc_portugues. pdf\&mde=ProdItem\&cod=37>. Acesso em: 25 set. 2017.

JACOBI, Pedro Roberto; BARBI, Fabiana. Democracia e participação na gestão dos recursos hídricos no Brasil. Rev. Katál, Florianópolis, v. 10, n. 2, jul./dez. 2007, p. 237-244.

JONAS, Hans. O princípio responsabilidade: ensaio de uma ética para a civilização tecnológica. Tradução Marijane Lisboa, Luiz Barros Montez. Rio de Janeiro: Contraponto: Ed. PUC-Rio, 
2006.

LACABANA, Miguel. Acesso social à água e políticas públicas: o caso das Mesas Técnicas de Água na Venezuela. In: O direito à água como política pública na América Latina : uma exploração teórica e empírica. Brasília: Ipea, 2015.

LUCON, Oswaldo. Desenvolvimento Sustentável. In: REI, Fernando et al. (org.). Direito e desenvolvimento uma abordagem sustentável. São Paulo: Saraiva, 2013, p. 24-54.

MACHADO, Carlos José Saldanha. Recursos Hídricos e Cidadania no Brasil: Limites, Alternativas e Desafios. Ambiente \& Sociedade. vol. VI, $\mathrm{n}^{0}$ 2, p. 121-136, dez. 2003.

MARTINS, Rodrigo et al. Uso e gestão dos Recursos Hídricos no Brasil II Velhos e novos desafios para a cidadania. São Carlos: RiMa, Volume II. 2004.

MORAIS, José Luis Bolzan de; NASCIMENTO, Valéria Ribas do. Constitucionalismo e cidadania: por uma jurisdição constitucional democrática. Porto Alegre: Livraria do Advogado Editora, 2010.

OLIVEIRA, Celso Maran de et al. Democracia da água: das políticas internacionais à atuação de uma microbacia hidrográfica. Veredas do Direito: Direito Ambiental e Desenvolvimento

Sustentável, [S.l.], v. 11, n. 22, p. 271, ago. 2015. ISSN 21798699. Disponível em:

<http://www.domhelder.edu.br/revista/index.php/veredas/article/v iew/440>. Acesso em: 23 set. 2016.

doi:http://dx.doi.org/10.18623/rvd.v11i22.440.RIBEIRO, Wagner Costa. Água Doce: Conflitos e Segurança ambiental. In: MARTINS, Constante Martins, (org.). Uso e gestão dos recursos hídricos no Brasil: Desafios teóricos e político-institucionais. São Carlos: RIMA 2003.

. Geografia política da água. São Paulo: Annablume, 2008. (Coleção Cidadania e Meio Ambiente).ROESLER, M. R. von B. O Direito ao Meio Ambiente e a Água Saudável: avanços e desafios à governança compartilhada. In: Sociedade em Debate. Pelotas, v. $18, \mathrm{n}$. 1. Jan/ Jun 2012. Disponível em: <www.revistas.ucpel.tche.br/index.php/rsd/article/view/707>. Acesso em: Set. 2016. 
A Participação Popular Na Governança Da Água Como Reforço...

SHULTZ, Jim. A Guerra pela Água na Bolívia. Disponível em: $<$ http://www.article.19.org/work/regions/latinamerica/FOI/pdf/waterwar_Por.pdf/.>.Acesso em 10 out. 2016.

SILVA, Jairo Bezerra et al. Ambivalências e contradições do discurso sobre a escassez de água no Brasil e no mundo e da proposta de gestão racional de recursos hídricos. Raízes, Campina Grande, vol. 25, $\mathrm{n}^{0} \mathrm{~s} 1$ e 2, jan./dez. 2006, p. 26-36.

SILVA, Jairo Bezerra et al. A crise hídrica global e as propostas do Banco Mundial e da ONU para seu enfrentamento. Revista Cronos, v. 11, n. 2, 2012.

TURATTI, Luciana. Direito à água: uma ressignificação substancialmente democrática e solidária de sua governança. Tese. Doutorado em Direito. Programa

de Pós-Graduação em Direito - Mestrado e Doutorado em Direito, Universidade de

Santa Cruz do Sul - UNISC, 2014.

UNITED NATIONS EDUCATION, SCIENTIFIC AND CULTURAL ORGANIZATION (UNESCO). The United Nations World Development Report, WWDR. Disponível em:

$<$ http://www.unesco.org/new/en/naturalsciences/environment/water/wwap/wwdr $>$. Acesso em 30 set. 2016.

VENEZUELA. Programa de las Naciones Unidas para el Desarrollo (RBV-PNUD).

Metas del milenio. Caracas, 2005.

WHO e UNICEF (2000). Global Water Supply and Sanitation Assessment 2000 Report. The WHO and UNICEF Join Monitoring Program for Water Supply and Sanitation (JMP). Geneva, World Health Organization. 79p.

WILSON, E. O. Diversidade da Vida. São Paulo: Companhia das Letras, 1994WOLKMER, Antônio Carlos; AUGUSTIN, Sergio; WOLKMER, Maria de Fátima S. O "novo" direito à água no constitucionalismo da América Latina. Revista Internacional Interdisciplinar INTERthesis, Florianópolis, v. 9, n. 1, Jan./Jul. 2012, p. 51-69. 


\title{
Popular Participation In Water Governance As A Reinforcement Of Environmental Citizenship In The Democracies Of Latin America
}

\author{
Diego Monte Teixeira
}

Newton Menezes Albuquerque

\begin{abstract}
The article aims to analyze the challenges of popular participation in water governance in Latin America, especially the repercussions of this participation in democracy, in the reworking of its concepts and realities, both in the management of scarce natural resources and in the broader treatment, ethical, the nexus between rights and nature. With a field of study in the area of legal sciences, the legal-technical method was used through deductive reasoning in the analysis of some Constitutions of Latin American countries, doctrines, jurisprudence of International Courts, as well as scientific articles, to conclude that the introduction of the idea of environmental citizenship requires a redimensioning of the relations between man and nature, society and culture, overcoming the unilateralism existing in an anthropocentric conception that has traditionally guided the place of the person within the State. The results presented are that the increase of environmental citizenship in Latin American democracies must pass through popular participation in water governance, which should be conceived as a human right rather than a type of commodity.
\end{abstract}

Keywords: Water; Citizenship; Democracy; Latin America. 